\title{
Consistência da gordura abdominal de frango, de suas estearinas e de suas misturas binárias com toucinho
}

\author{
Ming Chih Chiu, Luiz Antonio Gioielli* \\ Departamento de Tecnologia Bioquímico-Farmacêutica, Faculdade de Ciências Farmacêuticas, \\ Universidade de São Paulo
}

*Correspondência:

L. A. Gioielli

Depto. de Tecnologia Bioquímico-

Farmacêutica

Faculdade de Ciências Farmacêuticas

Universidade de São Paulo

Av. Prof. Lineu Prestes, 580, Bloco 16

05508-900 - São Paulo, SP, Brasil

E-mail: lagio@usp.br

\begin{abstract}
A consistência é uma das propriedades fisicas mais importantes das gorduras, pois se encontra diretamente associada às suas diversas aplicações. Esta propriedade pode ser considerada como um aspecto funcional relevante das gorduras plásticas, que são misturas de cristais de gordura sólida e óleo líquido. Os cristais de gordura formam uma rede tridimensional, que comunica plasticidade ao material. O objetivo deste trabalho foi analisar as interações que ocorrem em misturas binárias de duas gorduras animais (abdominal de frango e de toucinho) quanto a sua propriedade de consistência em diferentes temperaturas. As amostras foram analisadas quanto à composição em ácidos graxos e à consistência, às temperaturas de 10 a $25{ }^{\circ} \mathrm{C}$. Utilizou-se o analisador de textura TA-XT2 (Stable Micro Systems). Aplicou-se um modelo de regressão múltipla do tipo quadrático. Os resultados demonstraram que ocorreu o efeito eutético entre as estearinas obtidas no fracionamento da gordura de frango e a gordura de toucinho. Por outro lado, nas misturas entre gordura de frango e gordura de toucinho ocorreu efeito sinérgico, caracterizando a formação de compostos.
\end{abstract}

Unitermos:

- Consistência

- Estearinas

- Gordura abdominal de frango

- Gordura de toucinho

- Misturas binárias

\section{INTRODUÇÃO}

A gordura abdominal de frango é um subproduto da industrialização do frango, apresentando altos teores dos ácidos graxos palmítico e oléico, e que pode ser aplicada na formulação de diferentes produtos alimentícios, tais como caldos desidratados, pós para sopa e patês. Os diversos atributos sensoriais de um alimento encontram-se diretamente associados às características físico-químicas da matéria-prima. De acordo com Correa-Cabrera et al. (1999), para algumas matérias-primas, em especial a gordura de frango, torna-se conveniente modificar o conteúdo em frações de baixos pontos de fusão, de modo a melhorar o seu comportamento térmico. Para isso, o fracionamento térmico controlado ou uma hidrogenação adicional podem ser utilizados, a fim de obter frações mais duras que permitam manter as características organolépticas, sem influenciar negativamente a estabilidade frente à variação de temperatura. A mistura também pode ser uma ferramenta na obtenção de bases gordurosas mais adequadas, visando à elaboração de diferentes produtos com características específicas, uma vez que permite combinar componentes sólidos e líquidos com características físico-químicas distintas, resultando em produtos que combinam parâmetros diversos.

A textura é definida como a manifestação sensorial da estrutura de um alimento e a maneira na qual esta reage à aplicação de uma força (Meullenet et al., 1997). Szczesniak 
$(1963,1987)$ sugeriu que as características da textura podem ser classificadas em três principais categorias: mecânica, geométrica e outras (principalmente umidade e gordura). Esta definição reconhece a textura como uma qualidade sensorial multidimensional e também como um atributo de múltiplos parâmetros, que se manifesta de diferentes formas. Alguns dos atributos sensoriais identificados como descritivos da textura de alimentos sólidos são: dureza, elasticidade, coesividade, fraturabilidade, coesividade de massa e mastigabilidade (Meullenet, Gross, 1999). A textura medida como consistência ou plasticidade é primariamente determinada pelas propriedades físicas dos óleos e gorduras (Lida, Ali, 1998). O "yield value" é influenciado diretamente pela cristalização das gorduras e corresponde à resistência da gordura à deformação.

As interações que ocorrem entre os triacilgliceróis nas misturas binárias são os principais fatores que influenciam os comportamentos de fusão e cristalização das gorduras. Gioielli (1996) e Sato, Ueno e Yano (1999) descreveram três tipos de sistemas binários que podem ser observados: soluções sólidas contínuas, sistema eutético e sistema monotético.

O objetivo deste trabalho foi analisar as interações que ocorrem em misturas binárias de gordura abdominal de frango e suas estearinas com uma gordura suína (toucinho), quanto à propriedade de consistência.

\section{MATERIAL E MÉTODOS}

\section{Material}

Foram utilizadas amostras brutas de gordura abdominal de frango de diferentes raças comerciais, gentilmente fornecidas pela microempresa avícola Koka Ltda., e gordura de toucinho (retirada do toucinho e a seguir fundida).

\section{Métodos}

\section{Fracionamento}

Foi realizado o fracionamento da gordura de frango por cristalização a seco às temperaturas de $17,5^{\circ} \mathrm{C}$ e $20{ }^{\circ} \mathrm{C}$, obedecendo-se as seguintes etapas:

- As amostras de gordura foram inicialmente fundidas em forno de microondas até a temperatura de $70{ }^{\circ} \mathrm{C}$, para assegurar a completa fusão dos cristais. Posteriormente, foram colocadas em estufa à temperatura de fracionamento.

- Após 24 horas a gordura parcialmente cristalizada foi filtrada sob pressão reduzida para separação das frações líquida (oleína) e sólida (estearina).
O fracionamento foi realizado sem programação de temperatura para o resfriamento e sem agitação.

\section{Mistura}

Para estudar as interações que ocorrem em misturas binárias, foi utilizado um planejamento de seis experimentos. As amostras foram preparadas por meio de misturas nas proporções mencionadas na Tabela I, após fusão completa das gorduras individuais à temperatura de $60-70{ }^{\circ} \mathrm{C}$. Foram realizadas misturas da gordura de toucinho com gordura de frango, com estearina obtida a $17,5^{\circ} \mathrm{C}$ de gordura de frango e com estearina obtida a $20^{\circ} \mathrm{C}$ de gordura de frango. Estas amostras foram novamente solidificadas e posteriormente armazenadas sob resfriamento.

TABELA I - Planejamento experimental das misturas binárias de gordura de toucinho com gordura de frango, com estearina obtida a $17,5^{\circ} \mathrm{C}$ de gordura de frango e com estearina obtida a $20{ }^{\circ} \mathrm{C}$ de gordura de frango

\begin{tabular}{ccc}
\hline Amostra $\left(\mathrm{n}^{\circ}\right)$ & \multicolumn{2}{c}{ Proporção $(\% \mathrm{p} / \mathrm{p})$} \\
\cline { 2 - 3 } & $\mathrm{x}_{1}$ & $\mathrm{x}_{2}$ \\
\hline 1 & 100 & 0 \\
2 & 80 & 20 \\
3 & 60 & 40 \\
4 & 40 & 60 \\
5 & 20 & 80 \\
6 & 0 & 100 \\
\hline
\end{tabular}

onde:

$\mathrm{x}_{1}=$ gordura de frango, ou estearina a $17,5^{\circ} \mathrm{C}$, ou estearina a $20{ }^{\circ} \mathrm{C}$;

$\mathrm{x}_{2}=$ gordura de toucinho

Para a resposta analítica foi aplicado um modelo de regressão múltipla, do tipo quadrático (Hare, 1974), representado pela seguinte equação:

$$
y=\beta_{1} x_{1}+\beta_{2} x_{2}+\beta_{12} x_{1} x_{2}
$$

Onde:

$\mathrm{y}=$ resposta

$\beta=$ coeficientes gerados por regressão múltipla

$\mathrm{x}=$ proporção dos componentes

Foi utilizado o aplicativo Statgraphics versão 2.6, que permitiu a obtenção dos coeficientes para o modelo, além de apresentar seus níveis de significância, coeficientes de determinação e análise de variância. 


\section{Consistência}

As amostras de gordura foram aquecidas à temperatura de $60-70{ }^{\circ} \mathrm{C}$ em forno de microondas para completa fusão dos cristais, sendo acondicionadas em béqueres de $50 \mathrm{~mL}$. O condicionamento foi efetuado por 24 horas em geladeira comum $\left(5-8^{\circ} \mathrm{C}\right)$ e em seguida por 24 horas em estufa com temperatura controlada (temperatura de análise $\pm 0,5^{\circ} \mathrm{C}$ ).

A análise de consistência foi efetuada por meio de teste de penetração com cone de acrílico de ângulo $45^{\circ}$, em analisador de textura TA-XT2, da Stable Micro Systems, controlado por microcomputador.

Os testes foram conduzidos em duplicata nas seguintes condições: determinação da força em compressão; distância: $10,0 \mathrm{~mm}$; velocidade: $2,0 \mathrm{~mm} / \mathrm{s}$; tempo: $5 \mathrm{~s}$.

Para realizar a conversão dos dados de penetração em um parâmetro independente de peso e do tipo de cone, foi utilizada a equação proposta por Haighton (1959), para o cálculo do "yield value":

$$
\mathrm{C}=\mathrm{K} \cdot \mathrm{W} / \mathrm{p}^{1,6}
$$

Onde:

$\mathrm{C}=$ "yield value", em $\mathrm{gf} / \mathrm{cm}^{2}$

$\mathrm{K}=$ fator que depende do ângulo do cone (para ângulo de $45^{\circ}, \mathrm{K}$ é igual a 4.700 )

$\mathrm{W}=$ peso total do sistema, em $\mathrm{g}$ (para penetrômetro de cone)

$\mathrm{P}=$ profundidade de penetração, em $0,1 \mathrm{~mm}$.

Considerando as condições dos testes de compressão realizados com o analisador de textura, a equação assume a seguinte forma:

$\mathrm{C}=4700 . \mathrm{W} / 100^{1.6}$

Onde:

$\mathrm{C}=$ "yield value", em $\mathrm{gf} / \mathrm{cm}^{2}$

$\mathrm{W}=$ força em compressão, em gf, para tempo $=5 \mathrm{~s}$.

A consistência foi analisada às temperaturas de 10 , 15,20 e $25^{\circ} \mathrm{C}$.

\section{Composição em ácidos graxos}

A análise de ácidos graxos foi realizada por cromatografia em fase gasosa, segundo normas da AOCS (1998), método Ce 1-62, em cromatógrafo a gás Varian GC, modelo 3400CX, equipado com detector de ionização de chama e integrador eletrônico modelo CG-300. Foi utilizada coluna capilar de sílica fundida VA-WAX (Varian), com $30 \mathrm{~m}$ de comprimento x 0,25 mm de diâme- tro interno e contendo $0,25 \mathrm{~mm}$ de polietilenoglicol. As condições foram: injeção split, razão de 50:1; temperatura da coluna: $150{ }^{\circ} \mathrm{C}$ por 11 minutos, programada até $210{ }^{\circ} \mathrm{C}$ à razão de $3{ }^{\circ} \mathrm{C}$ por minuto; gás de arraste: hélio, vazão de 1,5 $\mathrm{mL}$ por minuto; gás make-up: hélio a $30 \mathrm{~mL}$ por minuto; temperatura do injetor: $250{ }^{\circ} \mathrm{C}$; temperatura do detector: $280^{\circ} \mathrm{C}$. A composição qualitativa foi determinada por comparação dos tempos de retenção dos picos com os dos respectivos padrões de ácidos graxos. A composição quantitativa foi realizada por normalização de área, sendo expressa como porcentagem em massa.

Os ésteres metílicos de ácidos graxos para a análise foram obtidos pela saponificação de $150-200 \mathrm{mg}$ de amostra com 3,5 mL de solução metanólica $0,5 \mathrm{~N}$ de hidróxido de potássio, fervendo-se por 3-5 min em banho de água a $75-80^{\circ} \mathrm{C}$. À solução quente foram adicionados $10,5 \mathrm{~mL}$ do reagente de esterificação. A mistura foi refluxada por cerca de 3 min e transferida para um funil de separação, adicionando-se $20 \mathrm{~mL}$ de éter de petróleo e $40 \mathrm{~mL}$ de água destilada. A camada aquosa foi descartada e a camada de éter de petróleo lavada duas vezes com $20 \mathrm{~mL}$ de água destilada. As camadas aquosas foram também descartadas. A camada de éter de petróleo foi transferida para um tubo de ensaio com tampa. O solvente foi evaporado em banho-maria a $40{ }^{\circ} \mathrm{C}$, sob corrente de nitrogênio. Adicionou-se hexano como solvente para a realização das análises. As amostras foram armazenadas a $20^{\circ} \mathrm{C}$ negativos (Hartman, Lago, 1973).

O índice de iodo foi calculado a partir da composição em ácidos graxos segundos as normas da American Oil Chemists' Society (1998), método Cd 1c-85. O resultado foi expresso em $\mathrm{g}$ de iodo/100 $\mathrm{g}$ de gordura. O índice de saponificação foi calculado a partir da composição em ácidos graxos, em função da definição do índice, que corresponde ao número de $\mathrm{mg}$ de hidróxido de potássio necessárias para saponificar uma grama de óleo ou gordura (Singhal, Kulkarni, 1990).

\section{RESULTADOS}

A Tabela II apresenta a composição em ácidos graxos e os índices de iodo e de saponificação da gordura de frango e de suas frações e da gordura de toucinho. A Tabela III apresenta os coeficientes calculados por regressão múltipla a partir dos resultados experimentais da consistência das misturas binárias de gordura de frango com gordura de toucinho (A), estearinas a $17,5^{\circ} \mathrm{C}$ de gordura de frango com gordura de toucinho (B) e estearinas a $20^{\circ} \mathrm{C}$ de gordura de frango com gordura de toucinho (C). A Figura 1 apresenta os dados da consistência em função da temperatura para misturas binárias de estearinas a 
$17,5^{\circ} \mathrm{C}$ de gordura de frango com gordura de toucinho. A Figura 2 apresenta os dados da consistência em função da temperatura para misturas binárias de estearinas a $20^{\circ} \mathrm{C}$ de gordura de frango com gordura de toucinho. A Figura 3 apresenta os dados da consistência em função da temperatura para misturas de gordura de frango com gordura de toucinho. A Figura 4 apresenta as curvas de iso-consistências das misturas binárias de gordura de frango com gordura de toucinho. A Figura 5 apresenta as curvas de isoconsistências das misturas binárias de estearina de gordura de frango a $17,5^{\circ} \mathrm{C}$ com gordura de toucinho. A Figura 6 apresenta as curvas iso-consistências das misturas binárias de estearina de gordura de frango a $20^{\circ} \mathrm{C}$ com gordura de toucinho.

\section{DISCUSSÃO}

Os resultados encontrados para a composição em ácidos graxos da gordura de frango e para os índices de iodo e saponificação (Tabela II) estiveram compatíveis com a literatura consultada, apresentando diferença máxima ao redor de 5\% para o ácido oléico (Orthoefer, 1996; Stauffer, 1996; Vizcarrondo, De Padilla, Martin 1998; Chiu, Gomes, 1998). Esta diferença provavelmente é devida a fatores intrínsecos às aves, tais como idade, sexo, raça, tipo de alimentação, clima e o tecido adiposo analisado (Biondic, 1976). Os resultados obtidos para os mesmos parâmetros mencionados, para a gordura de toucinho, estiveram de acordo com a literatura pesquisada (Love, 1996; Gunstone et al., 1986; Rossel, 1986; Stauffer, 1996). A composição em ácidos graxos da gordura de toucinho varia de acordo com a alimentação, origem, espécie e localização da gordura presente no suíno (Gunstone, Harwood, Padley, 1986). Esta gordura contém quantidades consideráveis dos ácidos palmítico, esteárico, oléico e linoléico. Sua composição em triacilgliceróis compreende 7\% de trissaturados e 30\% de dissaturados. Quando comparada ao sebo bovino, a gordura de toucinho apresenta maior quantidade de triacilgliceróis com duas duplas ligações e com três duplas ligações. Animais não-ruminantes como os suínos incorporam rapidamente os ácidos graxos insaturados da dieta em seus depósitos teciduais de gordura (Love, 1996). Devido a este comportamento metabólico, a gordura de toucinho apresenta elevados índices de ácidos graxos insaturados como o ácido oléico $(47,1 \%)$.

As estearinas da gordura de frango apresentaram maior quantidade de ácidos graxos saturados quando comparadas às oleínas. Correa-Cabrera et al. (1999) relataram que para algumas matérias-primas, em especial a gordura de frango, torna-se conveniente modificar o conteúdo em frações de baixos pontos de fusão, de modo a melhorar o seu comportamento térmico. Assim, o fracionamento térmico controlado ou a hidrogenação parcial podem ser utilizados a fim de obter frações mais duras que permitam manter as características organolépticas sem influenciar negativamente a estabilidade frente à variação de temperatura.

$\mathrm{O}$ índice de iodo da gordura de frango esteve próximo ao citado por Biondic (1976), que relatou valor de 78,5. Entretanto, o índice de saponificação relatado foi de 184,7, enquanto que neste estudo obteve-se 196,9. Ambas as estearinas apresentaram menores valores de índice de iodo em relação à gordura de frango devido ao maior teor

TABELA II - Composição em ácidos graxos e índices de iodo e de saponificação da gordura de frango e suas frações, e da gordura de toucinho

\begin{tabular}{ccccccr}
\hline ÁCIDOS & \multicolumn{7}{c}{ AMOSTRAS } \\
\cline { 2 - 7 } GRAXOS & Estearina & Estearina & Oleína & Oleína & Gordura de & Gordura de \\
$(\%)$ & $\mathrm{a} 17,5^{\circ} \mathrm{C}$ & $\mathrm{a} 20^{\circ} \mathrm{C}$ & $\mathrm{a} 17,5^{\circ} \mathrm{C}$ & $\mathrm{a} 20^{\circ} \mathrm{C}$ & Frango & Toucinho \\
\hline $14: 0$ & 0,8 & 0,7 & 0,4 & 0,7 & 0,9 & 1,4 \\
$16: 0$ & 32,9 & 33,9 & 23,5 & 24,1 & 26,4 & 23,5 \\
$16: 1$ & 6,3 & 6,0 & 8,0 & 7,9 & 7,3 & 2,3 \\
$18: 0$ & 8,5 & 9,3 & 5,0 & 5,3 & 5,5 & 10,8 \\
$18: 1$ & 35,2 & 34,3 & 42,4 & 42,0 & 37,5 & 47,1 \\
$18: 2$ & 15,3 & 14,7 & 19,5 & 18,8 & 21,2 & 14,3 \\
$18: 3$ & 1,0 & 1,0 & 1,2 & 1,1 & 1,2 & 0,6 \\
I.I* & 65,3 & 63,3 & 80,9 & 79,2 & 79,1 & 69,1 \\
I.S* & 197,7 & 197,8 & 196,3 & 196,5 & 196,9 & 195,4 \\
\hline
\end{tabular}

*I.I. $=$ Índice de iodo $(\mathrm{g}$ iodo $/ 100 \mathrm{~g})$.

*I.S. = Índice de saponificação (mg KOH/g) 
de ácidos graxos saturados presentes nestas duas frações. As oleínas apresentaram índices de iodo similares à gordura de frango. O teor de ácido oléico nas oleínas foi maior que para a gordura de frango, embora o teor de ácido linoléico tenha sido menor. Isto pode ser devido ao fato de que o ácido linoléico se encontra presente nos triacilgliceróis que apresentam, principalmente, ácido graxos saturado na sua composição. Com relação ao índice de saponificação pode-se observar que a diferença entre a gordura de frango e suas frações foi mínima, porque o peso molecular médio dos ácidos graxos nas gorduras é praticamente o mesmo.

É possível comparar as amostras em função da propriedade subjetiva de espalhabilidade, usando os critérios estabelecidos por Haighton (1959). A gordura de frango à temperatura de $10^{\circ} \mathrm{C}$ apresentou-se plástica e espalhável, enquanto a estearina obtida a $20^{\circ} \mathrm{C}$, à temperatura de $20^{\circ} \mathrm{C}$, mostrou-se dura, mas satisfatoriamente espalhável. Já a estearina a obtida a $17,5^{\circ} \mathrm{C}$, na mesma temperatura, apresentou-se plástica e espalhável. Os resultados da consistência em função da temperatura são apresentados nas Figuras de 1 a 3, calculada como "yield value", em gf $/ \mathrm{cm}^{2}$. As gorduras comportam-se como sólidos rígidos até que o "stress" de deformação exceda o "yield value", quando começam a fluir como um líquido viscoso (Deman, Beers, 1988).

Observa-se, nas Figuras 1, 2 e 3, que as amostras apresentaram grande diminuição da consistência na faixa de temperatura de 10 a $20^{\circ} \mathrm{C}$, com exceção da gordura de toucinho, que apresentou queda suave a partir de $15{ }^{\circ} \mathrm{C}$ (Figura 3).

Produtos com "yield value" na faixa de 200 a $800 \mathrm{~g} / \mathrm{cm}^{2}$ são os mais satisfatórios do ponto de vista de espalhabilidade. As misturas de gordura abdominal de frango com gordura de toucinho à temperatura de $10^{\circ} \mathrm{C}$ apresentaram-se dentro desta faixa de consistência, evidenciando que são adequadas para a elaboração de margarinas. O mesmo ocorre com as misturas das estearinas com gordura de toucinho na proporção de 20:80. Estas misturas, nas demais proporções, apresentaram consistência elevada ("yield value" acima de $1500 \mathrm{~g} / \mathrm{cm}^{2}$ ), com características muito duras. De acordo com Arciszewski (1996), o efeito de óleos e gorduras na maciez de produtos gordurosos e de panificação é relevante. Em produtos como as margarinas, por exemplo, a textura é um parâmetro muito importante, pois estes produtos precisam ter boas propriedades de espalhabilidade sob refrigeração e não liberar óleos quando expostos à temperatura ambiente (Deman, Deman, Blackman, 1995).

O conteúdo de gordura sólida e a consistência são parâmetros físico-químicos que se encontram estreitamente associados. Estes dois parâmetros são os principais responsáveis pelas características que permitem o uso de gorduras em aplicações específicas para a elaboração de produtos alimentícios (Lannes, Gioielli, 1995; Balbo, Gioielli, 1991; Lefebvre, 1983a, 1983b; Weiss, 1983, Haighton, 1976).

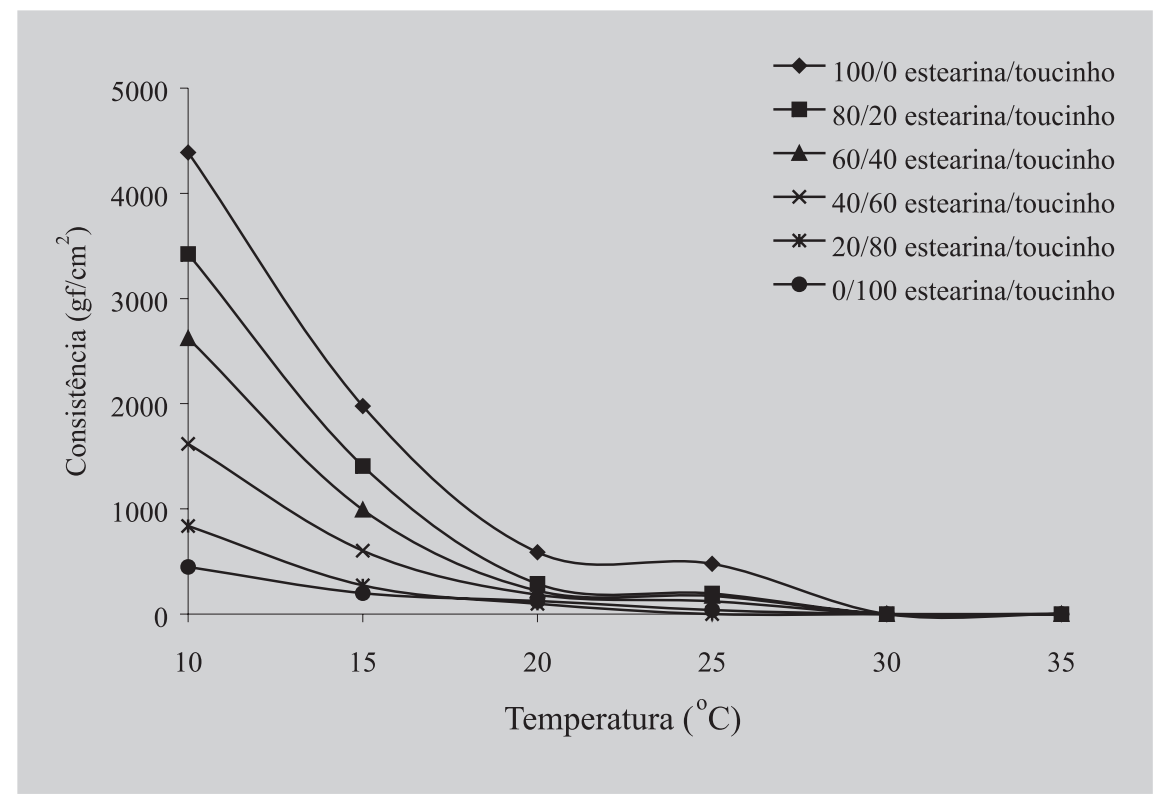

FIGURA 1 - Consistência em função da temperatura para misturas binárias de estearinas de gordura de frango a $17,5^{\circ} \mathrm{C}$ com gordura de toucinho. 


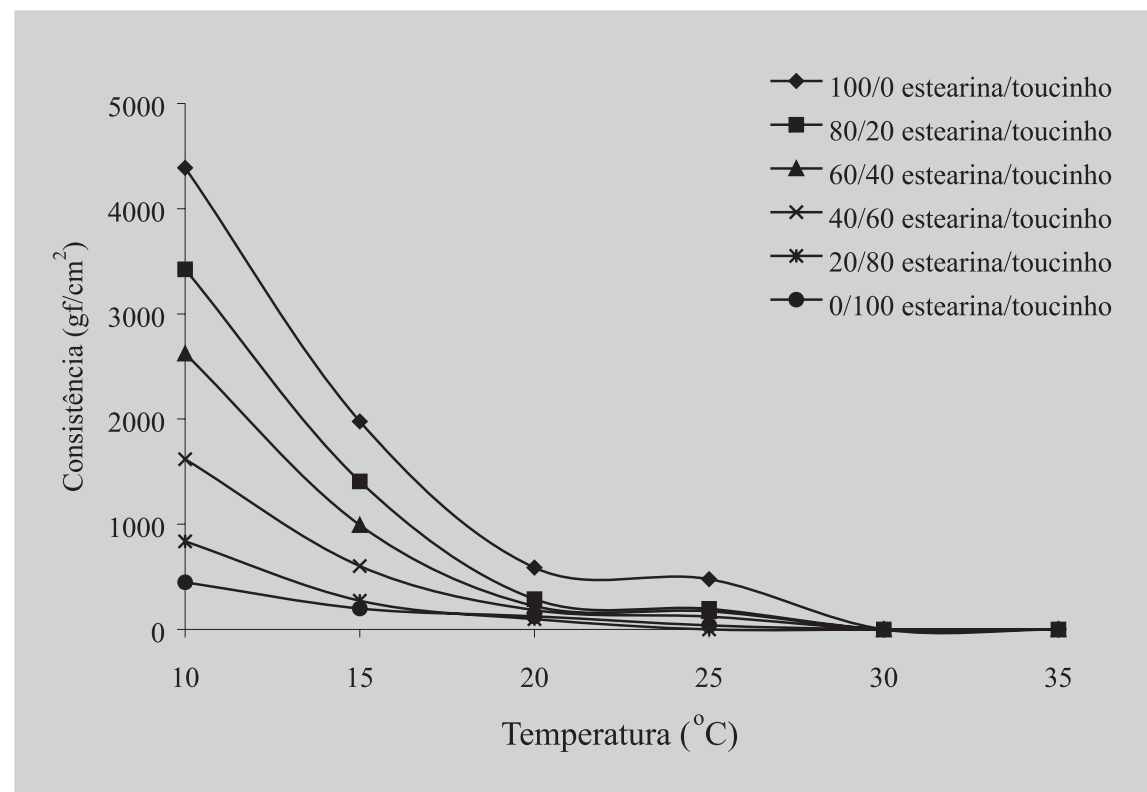

FIGURA 2 - Consistência em função da temperatura para misturas binárias de estearinas de gordura de frango a $20^{\circ} \mathrm{C}$ com gordura de toucinho.

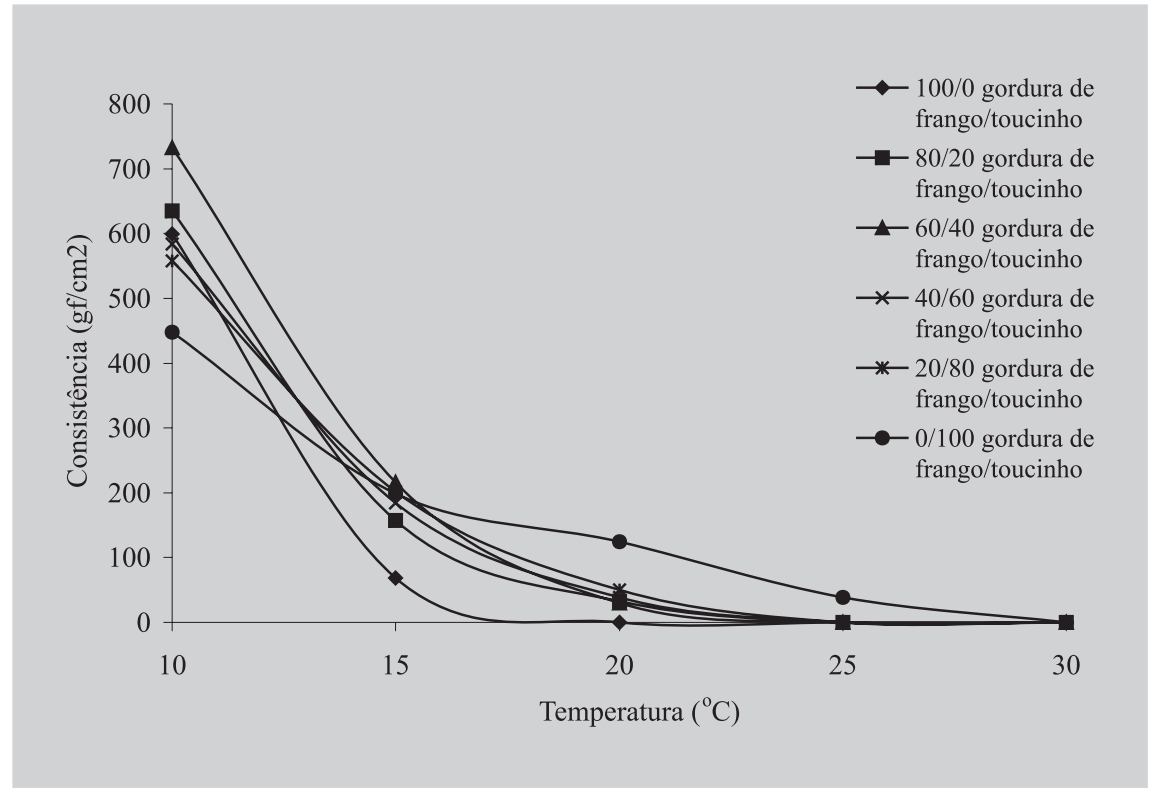

FIGURA 3 - Consistência em função da temperatura para misturas de gordura de frango com gordura de toucinho.

A Tabela III apresenta os coeficientes calculados por regressão múltipla a partir dos resultados experimentais da consistência. Os coeficientes não significativos ( $\mathrm{p}>0,05)$ foram eliminados. Os resultados mostraram que a gordura de frango não apresentou efeito na consistência a $20^{\circ} \mathrm{C}$, quando misturada à gordura de toucinho. Por outro lado, a gordura de toucinho não apresentou efeito significativo na consistência à temperatura de $25^{\circ} \mathrm{C}$, quando misturada à estearina obtida a $17,5^{\circ} \mathrm{C}$ ou quando em mistura com a estearina obtida a $20^{\circ} \mathrm{C}$, em qualquer temperatura. Neste último caso, a diferença de consistência entre as gorduras originais era acentuada, fazendo com que a gordura mais macia (toucinho) não apresentasse influência na consistência. Os coeficientes relativos às interações significativas entre as estearinas e a gordura de toucinho foram sempre negativos, demonstrando um efeito antagônico para a propriedade de consistência, característico das interações eutéticas entre triacilgliceróis ou entre gorduras. Este efei- 
to ocorre em função da pequena intersolubilidade no estado sólido dos triacilgliceróis e pode ser caracterizado pela depressão nas linhas de iso-consistência (Figuras 5 e 6), especialmente quando a proporção de gordura de toucinho está ao redor de $80 \%$.

Por outro lado, para as misturas binárias de gordura de frango com gordura de toucinho, os coeficientes relativos às interações foram positivos, nas temperaturas de $10^{\circ} \mathrm{C}$ e $15^{\circ} \mathrm{C}$, caracterizando a chamada formação de compostos (Timms, 1984; Birker, Padley, 1987). Neste caso, a interação resulta em empacotamento molecular favorável das cadeias de ácidos graxos, aumentando a consistência, em relação às gorduras originais. A Figura 4 evidencia este tipo de interação, apresentada pelas curvas de iso-consistência, mostrando que as misturas apresentam a mesma consistência quando condicionadas em temperaturas maiores. A formação de compostos ocorre em sistemas binários do tipo $\mathrm{PPO} / \mathrm{POP}, \mathrm{StPO} / \mathrm{POP}$, EPE/PEE e POP/OPO, onde $\mathrm{P}=$ palmítico, $\mathrm{O}=$ oléico, $\mathrm{St}=$ esteárico e $\mathrm{E}=$ elaídico. Essa interação ocorre em misturas de óleo de palma (com cerca de $30 \%$ de POP) e banha (com cerca de $50 \%$ de OPO). A mistura 1:1 de óleo de palma e banha contém $28 \%$ de sólidos a $22{ }^{\circ} \mathrm{C}$, enquanto os componentes apresentam $20 \mathrm{e}$ $22 \%$, respectivamente. Esse efeito é responsável pela arenosidade em margarinas produzidas com estas misturas. Outro exemplo é verificado na mistura de uma fração de óleo de palma interesterificada (com cerca de $66 \%$ de PPO) com uma fração intermediária de óleo de palma (rica em POP). Viau, Gandemer (1991) demonstraram que a gordura de frango apresenta em sua composição principalmente triacilgliceróis do tipo: $\mathrm{PO}_{2}, \mathrm{POL}, \mathrm{LO}_{2}, \mathrm{O}_{3}$ e $\mathrm{P}_{2} \mathrm{O}$, onde $\mathrm{P}=$ ácido palmítico, $\mathrm{O}=$ ácido oléico, $\mathrm{L}=$ ácido linoléico. $\mathrm{O}$ triacilglicerol do tipo $\mathrm{P}_{2} \mathrm{O}$ pode, portanto, ter levado a interação caracterizada pela formação de compostos nas misturas entre gordura abdominal de frango com a gordura de toucinho. Este tipo de interação é decorrente de um empacotamento molecular favorável das cadeias de ácidos graxos, resultando no aumento da consistência, quando comparada à consistência dos componentes individuais da mistura. Para que a formação de compostos ocorra, são necessárias as seguintes condições: a) mistura de trialcilgliceróis mono-insaturados simétricos e assimétricos; b)

TABELA III - Coeficientes calculados por regressão múltipla a partir dos resultados experimentais da consistência das misturas binárias de gordura de frango com gordura de toucinho (A), estearinas a $17,5^{\circ} \mathrm{C}$ de gordura de frango com gordura de toucinho (B) e estearinas a $20^{\circ} \mathrm{C}$ de gordura de frango com gordura de toucinho (C)

\begin{tabular}{|c|c|c|c|c|}
\hline \multirow[t]{2}{*}{ RESULTADO } & \multicolumn{4}{|c|}{ COEFICIENTES } \\
\hline & $\beta_{1}$ & $\beta_{2}$ & $\beta_{12}$ & $\mathrm{R}^{2}$ \\
\hline \multicolumn{5}{|l|}{ (A) } \\
\hline \multicolumn{5}{|l|}{ CONSISTÊNCIA } \\
\hline \multicolumn{5}{|l|}{$\mathrm{A}$} \\
\hline $10^{\circ} \mathrm{C}$ & 0,6008 & 0,4385 & 0,5468 & 0,9965 \\
\hline $15^{\circ} \mathrm{C}$ & 0,0799 & 0,1876 & 0,2794 & 0,9898 \\
\hline $20^{\circ} \mathrm{C}$ & 0 & 0,1108 & 0 & 0,9415 \\
\hline \multicolumn{5}{|l|}{ (B) } \\
\hline \multicolumn{5}{|l|}{ CONSISTÊNCIA } \\
\hline \multicolumn{5}{|l|}{$\mathrm{A}$} \\
\hline $10^{\circ} \mathrm{C}$ & 4,4347 & 0,4436 & $-1,439$ & 0,9985 \\
\hline $15^{\circ} \mathrm{C}$ & 2,1414 & 0,2232 & $-1,7278$ & 0,9976 \\
\hline $20^{\circ} \mathrm{C}$ & 0,5514 & 0,1341 & $-0,6911$ & 0,9837 \\
\hline $25^{\circ} \mathrm{C}$ & 0,4418 & 0 & 0 & 0,9626 \\
\hline \multicolumn{5}{|l|}{ (C) } \\
\hline \multicolumn{5}{|l|}{ CONSISTÊNCIA } \\
\hline \multicolumn{5}{|l|}{$\mathrm{A}$} \\
\hline $10^{\circ} \mathrm{C}$ & 5,6276 & 0 & 0 & 0,9972 \\
\hline $15^{\circ} \mathrm{C}$ & 2,5823 & 0 & $-1,2312$ & 0,9963 \\
\hline $20^{\circ} \mathrm{C}$ & 0,8947 & 0 & $-1,1759$ & 0,9773 \\
\hline $25^{\circ} \mathrm{C}$ & 0,6635 & 0 & $-0,8671$ & 0,9851 \\
\hline
\end{tabular}


trialcilgliceróis simétricos contendo somente um tipo de ácido graxo saturado; c) trialcilgliceróis assimétricos contendo dois ácidos graxos saturados diferentes, desde que o ácido comum a ambos acilgliceróis esteja na posição sn-2. Quando estas condições ocorrem, as cadeias de ácidos graxos empacotam formando três ácidos idênticos lado a lado. De acordo com D'Agostini, Ferraz, Gioielli (2000), as interações que ocorrem entre os triacilgliceróis nas mistu- ras binárias e ternárias de óleos e gorduras são os principais fatores que influenciam o comportamento das matérias graxas quanto à sua fusão e cristalização.

O nível de significância encontrado para os modelos foi $>94 \%$. Pela Tabela III, pode ser observado que a variação das respostas $\left(\mathrm{R}^{2}=0,9415\right.$ a 0,9985$)$ pode ser explicada pelas regressões múltiplas, indicando excelente ajuste do modelo aos dados experimentais.

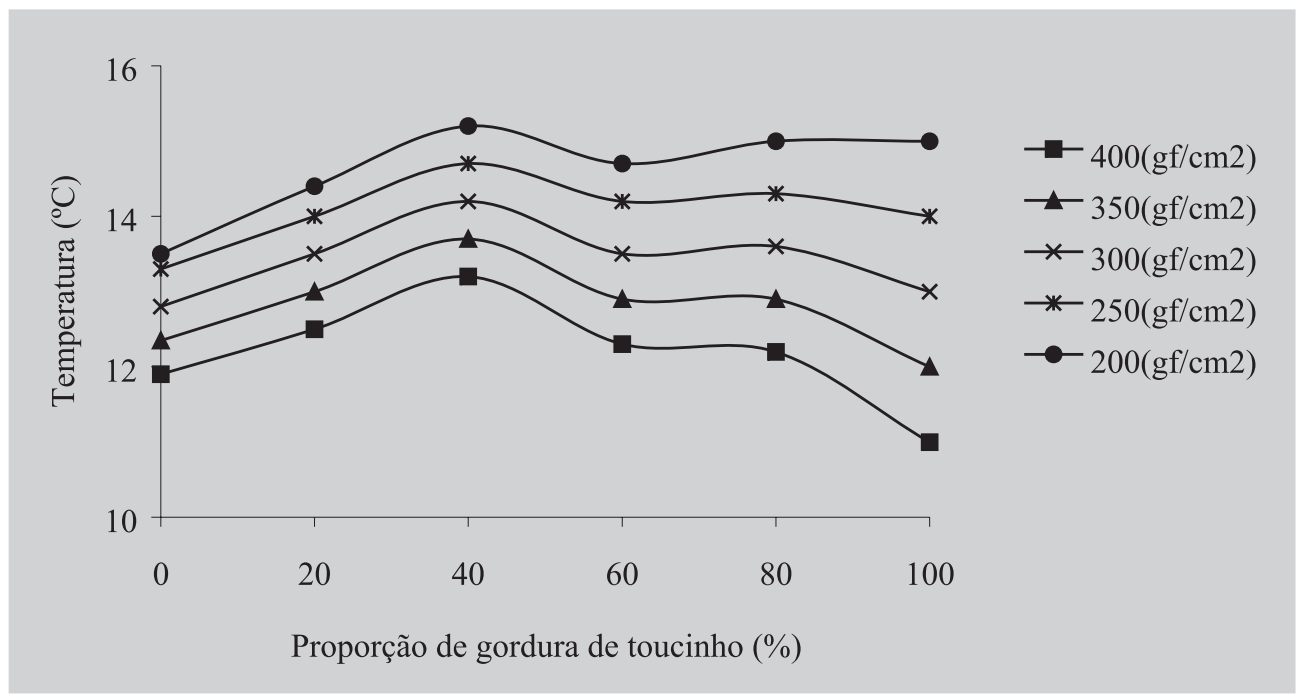

FIGURA 4 - Diagrama de curvas de iso-consistências das misturas binárias de gordura de frango com gordura de toucinho.

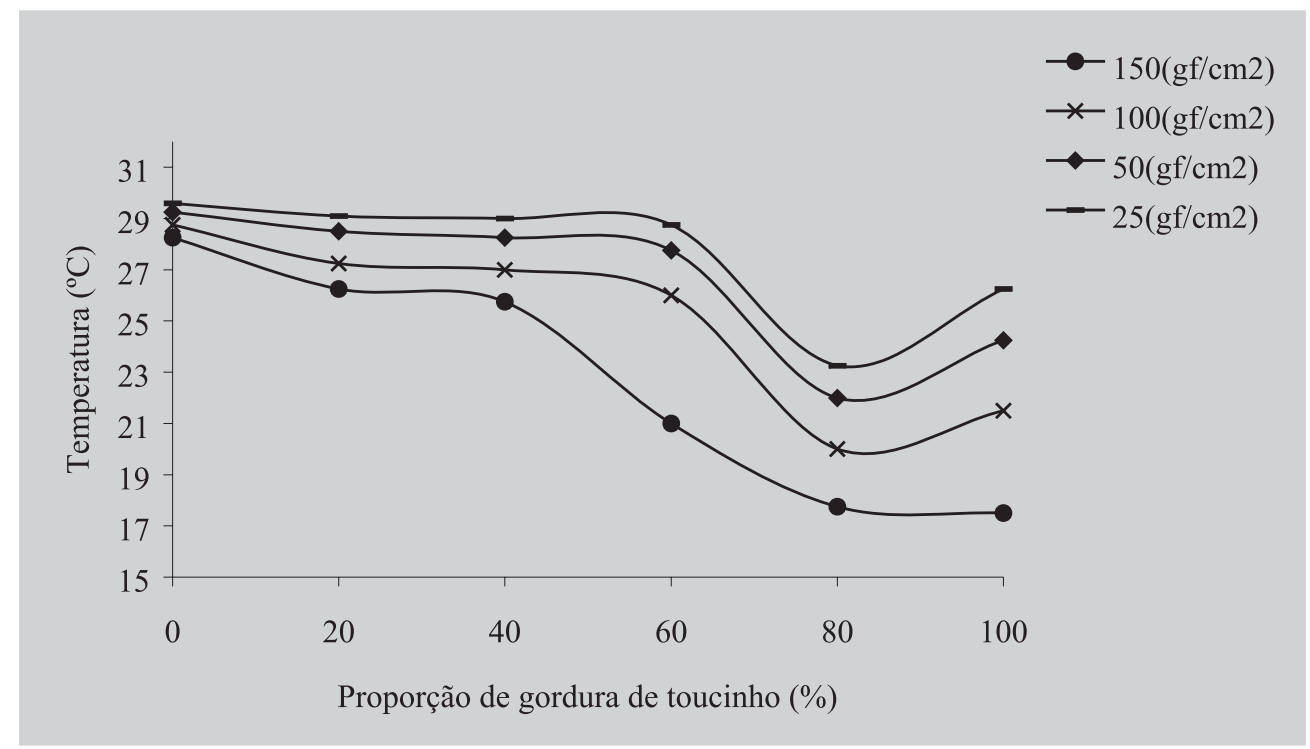

FIGURA 5 - Diagrama de curvas de iso-consistências das misturas binárias de estearina de gordura de frango a $17,5^{\circ} \mathrm{C}$ com gordura de toucinho. 


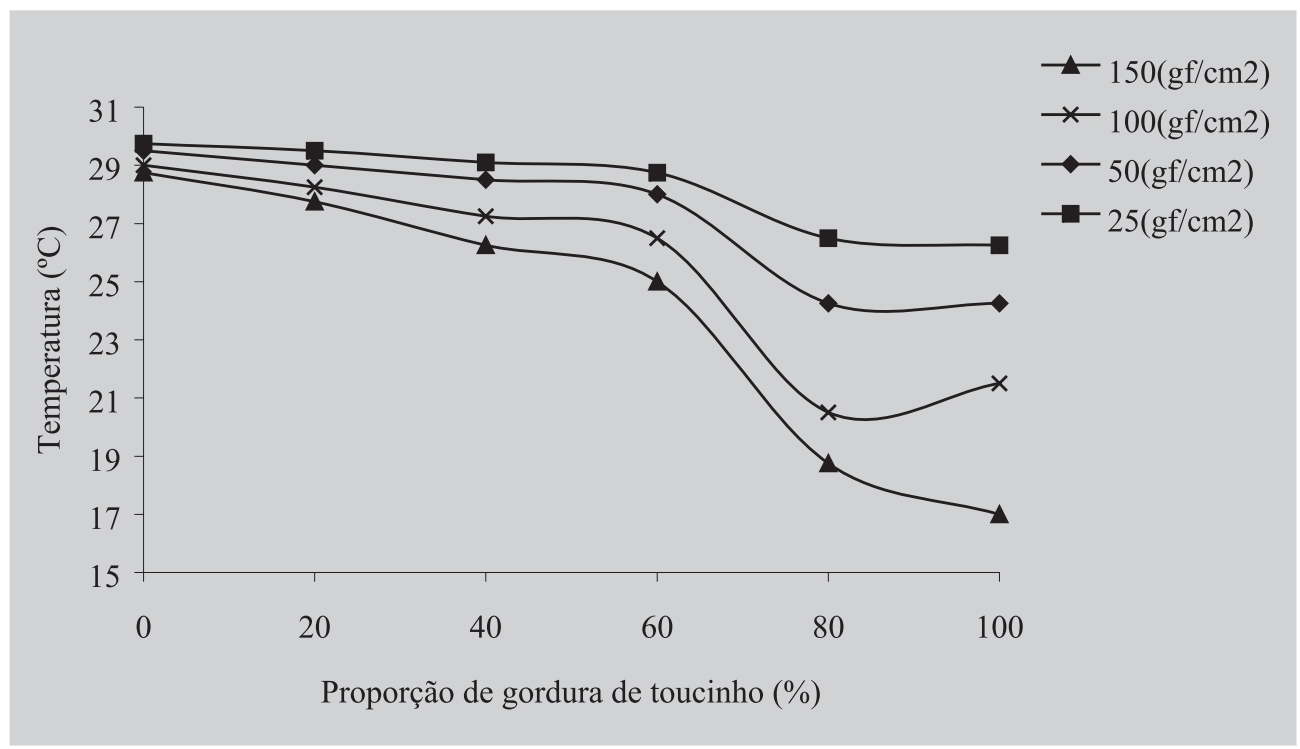

FIGURA 6 - Diagrama de curvas de iso-consistências das misturas binárias de estearina de gordura de frango a $20^{\circ} \mathrm{C}$ com gordura de toucinho.

\section{CONCLUSÕES}

A consistência das misturas binárias dependeu da gordura abdominal de frango e de suas frações e da gordura de toucinho. Os coeficientes negativos para a consistência demonstraram efeito antagônico, característico das interações eutéticas entre gorduras, que ocorreu com as misturas binárias das estearinas com a gordura de toucinho. Os coeficientes positivos demonstraram efeito sinérgico, caracterizando a chamada formação de compostos entre misturas de gorduras, que foi observado com a mistura binária da gordura abdominal de frango com a gordura de toucinho.

\section{ABSTRACT \\ Consistency of abdominal chicken fat, of its stearins and of its binary mixtures with bacon fat}

Consistency is one of the most important physical properties of fats since it is directly associated with its several applications. This property can be considered an important functional aspect of the plastic fats, which are a mixture of solid and liquid fat phase. The fat solid phase forms a tridimentional lattice arising plasticity to the fat. The objective of this paper was to analyze the interactions that occur in binary mixtures of two animal fats (abdominal chicken fat and bacon fat), regarding their consistency at different temperatures. The samples were analyzed for the fatty acid composition and for the consistency at the temperatures of 10 to $25^{\circ} \mathrm{C}$. The texture analyzer TA-XT2 (Stable Micro Systems) was utilized. A mathematical model of multiple regression of the quadratic type was applied. The results showed that the eutectic effect was observed between the binary mixtures of stearins and bacon fat. On the other hand, mixtures between abdominal chicken fat and bacon fat showed a synergic effect (compound formation).

UNITERMS: Consistency. Stearins. Abdominal chicken fat. Bacon fat. Binary mixtures.

\section{AGRADECIMENTOS}

À Fundação de Amparo à Pesquisa do Estado de São Paulo - FAPESP, à Fundação Coordenação de Aperfeiçoamento de Pessoal de Nível Superior - CAPES e ao Conselho Nacional de Desenvolvimento Científico e Tecnológico - CNPq, pelo auxílio financeiro e pelas bolsas concedidas aos autores.

\section{REFERÊNCIAS BIBLIOGRÁFICAS}

AMERICAN OIL CHEMISTS' SOCIETY. Official methods and recommended practices of the AOCS. 4. ed. Champaign, 1998.

ARCISZEWSKI, H. Funcionalidade de gorduras, redução em produtos de panificação. Óleos \& Grãos, São Caetano do Sul, n.28, p.25-29, 1996. 
BALBO, A. M. T .M., GIOIELLI, L. A. Mixtures of babassu fat with palm oil and its fractions: eutectic interactions. In: INTERNACIONAL MEETING ON FATS \& OILS TECHNOLOGY, 1, Campinas, 1991. Proceedings. Campinas: UNICAMP GTZ, 1991. p.184-188.

BIONDIC, B. Gordura de galinha e frango. Ind. Alim., Campinas, n.1, p.25-29, 1976.

BIRKER, P. J. M. W. L., PADLEY, F. B. Physical properties of fats and oils. In: HAMILTON, R. J., BHATI, A., eds. Recent advances in chemistry and technology of fats and oils. London: Elsevier, 1987. p.1-11.

CHIU, M. C., GOMES, M. Estudo da viabilidade para aproveitamento da gordura de aves de corte (frango). In: SIMPÓSIO DE INICIAÇÃO CIENTÍFICA DA UNIVERSIDADE DE SÃO PAULO, 6, São Carlos, 1998. Resumos. São Carlos: EESC USP, 1998. p. 457, abstr.n.11.08.

CORREA-CABRERA, R., CAPOTE, A., RODRÍGUEZAYÁN, M. N., GROMPONE, M. A. Caracterización de grasas para caldos deshidratados. Grasas Aceites, Seville, v.50, n.1, p.30-36, 1999.

D’AGOSTINI, D., FERRAZ, R. C., GIOIELLI, L. A. Consistência de misturas binárias e ternárias de gorduras de palma, palmiste e triacilgliceróis de cadeia média. Rev. Bras. Ciên. Farm., São Paulo, v.36, n.1, p.147-155, 2000.

DEMAN, J. M., BEERS, A. M. Fat crystal networks: structure and rheological properties. J. Texture Stud., Westport, v.18, n.4, p.303-318, 1988.

DEMAN, L., DEMAN, J. M., BLACKMAN, B. Effect of tempering on the texture and polymorphic behaviour of margarine fats. Fat Sci. Technol., Weinheim, v.97, n.2, p.55-60, 1995.

GIOIELLI, L. A. Misturas de óleos e gorduras na formulação de produtos gordurosos. Óleos \& Grãos, São Caetano do Sul, n.32, p.24-28, 1996.

GROMPONE, M. A., GUERRA, J. F., PAZOS, N. A., MÉNDEZ, E., LUCAS, E., JACHMANIÁN, I., COLLAZI, P. Fraccionamiento térmico de aceite de pollo. Grasas Aceites, Seville, v.45, n.6, p.390-344, 1994.
GUNSTONE, F. D., HARWOOD, J. L., PADLEY, F. B. The lipid handbook. Cambridge: The University Press, 1986. p.113-129.

HAIGHTON, A. J. Blending chiling, and tempering of margarines and shortenings. J. Am. Oil Chem. Soc., Champaign, v.53, n.6, p.397-399, 1976.

HAIGHTON, A. J. The measurement of the hardness of margarine and fats with cone penetrometers. J. Am. Oil Chem. Soc., Champaign, v.36, n.8, p.345-348, 1959.

HARE, L. B. Mixture designs applied to food formulation. Food Technol., Chicago, v.28, n.3, p.50-62, 1974.

HARTMAN, L., LAGO, R. C. A. A rapid preparation of fatty acid methyl esters from lipids. Lab. Pract., London, v.22, p.475-476, 1973 .

LANNES, S. C. S., GIOIELLI, L. A. Características físicoquímicas da manteiga de cacau e sucedâneos comerciais. Ciênc. Tecnol. Aliment., Campinas, v.15, n.1, p.89-94, 1995.

LEFEBVRE, J. Finished product formulation. J. Am. Oil Chem. Soc., Champaign, v.60, n.2, p.295-300, 1983 a.

LEFEBVRE, J. Formulation et gestion de la qualité en margarinerie. Rev. Fr. Corps Gras, Paris, v.30, n.2, p.59$65,1983 b$.

LIDA, H. M. D. N., ALI, A. R. M. Physicochemical characteristics of palm-based oil blends for the production of reduced fat spreads. J. Am. Oil Chem. Soc., Champaign, v.75, n.11, p.1625-1631, 1998.

LOVE, J. A. Animal fats. In: HUI, Y. H., ed. Bailey's industrial oil and fat products. 5. ed. New York: Wiley, 1996. v.1, p.1-18.

MEULLENET, J. F. C., CARPENTER, J. A., LYON, B. G., LYON, C. E. Bi-cyclical instrument for assessing texture profile parameters and its relationship to sensory evaluation of texture. J. Texture Stud., Westport, v.28, n.1 p.101-118, 1997.

MEULLENET, J. F. C., GROSS, J. Instrumental single and double compression tests to predict sensory texture characteristics of foods. J. Texture Stud., Westport, v.30, n.2, p.167-180, 1999 . 
ORTHOEFER, F. T. Vegetable oils. In: HUI, Y. H., ed. Bailey's industrial oil and fat products. 5. ed. New York: Wiley, 1996. v.1, p.19-44.

ROSSEL, J. B. Classical analysis of oils and fats. In: HAMILTON, R. J., ROSSEL, J. B., eds. Analysis of oils and fats. London: Elsevier Applied Science, 1986. p.190.

SATO, K., UENO, S., YANO, J. Molecular interactions and kinetic properties of fats. Prog. Lipid Res., Oxford, v.38, p.91-116, 1999.

SINGHAL, R. S., KULKARNI, P. R. Efffect of puffing on oil characteristics of amaranth (Rajgeera) seeds. J. Am. Oil Chem. Soc., Champaign, v.67, n.12, p.952-954, 1990.

STAUFFER, C. E. Fats and Oils St. Paul: Eagan Press, 1996. p.19-43.

SZCZESNIAK, A. S. Classification of textural characteristics. J. Food Sci., Chicago, v.28, n.4, p.385389, 1963.
SZCZESNIAK, A. S. Sensory with instrumental texture measurements - an overview of recent developments. $J$. Texture Stud., Westport, v.18, n.1, p.1-15, 1987.

TIMMS, R.E. Phase behaviour of fats and their mixtures. Prog. Lipid Res., Oxford, v.23, n.1, p.1-38, 1984.

VIAU, M., GANDEMER, G. Principales caractéristiques de composition des graisses de volaille. Rev. Fr. Corps Gras, Paris, v.38, n.5-6, p.171-177, 1991.

VIZCARRONDO, C. A., DE PADILLA, F. C., MARTIN, E. Fatty acid composition of beef, pork, and poultry fresh cuts, and some of their processed products. Arch. Latin. Amer. Nutr., Caracas, v.48, n.4, p.354-358, 1998.

WEISS, T. J. Food oils and their uses. 2. ed. Westport: AVI, 1983. p.1-33.

Recebido para publicação em 26 de abril de 2001. 